\title{
Why Do People Enjoy Watching Natural Disasters and Human Violence on Television? A Reversal Theory Perspective
}

\author{
Mariona Portell \\ Universitat Autònoma de Barcelona
}

\author{
Etienne Mullet \\ Institute of Advanced Studies (EPHE) \\ Paris, France
}

\begin{abstract}
We explored the psychological links that may exist between people's choices of television program, conversation topics around the content of these programs, and people's perceived degree of threat associated with these programs. The theoretical framework of the study was reversal theory (Apter, 2001). Participants were presented with a series of questionnaires assessing the degree of threat associated with potentially stressful situations (e.g., running of the bulls), the degree of enjoyment associated with television programs dealing with these situations (e.g., watching a report about the running of the bulls), and the degree of enjoyment associated with participation in conversations about these programs. The overall finding was that (a) most people like to watch frightening television programs because they find these situations to be the most entertaining once their negative consequences have been removed, (b) most people like to choose conversation topics centered on risks and risky situations for the same reason, (c) some people dislike watching frightening television programs and do not preferentially choose conversation topics centered on risks and risky situations because these situations, although not real for them, are still highly stressful, and possibly psychologically harmful. We highlight the usefulness of the concept of protective frame in the domain of risk communication, risk perception, and risk behavior.
\end{abstract}

Keywords: media enjoyment; risk perception; threat; catastrophe; protective frame; reversal theory

Klein \& Weinstein (1997) report, "Daily headlines and cocktail party conversations are filled with information about carcinogens, natural disasters, new viruses, chronic illnesses, AIDS, and numerous other health and safety concerns" (p. 25 ). Why are people generally so attracted by natural disasters and human violence that they tend to put them at the center of their daily conversations? Why do some people tend to preferentially select frightening television programs? (Davie, 2001; Tamborini, Skalski, Lachlan, Westerman, Davis, \& Smith, 2005). This study explores the psychological links that may exist between people's choices of television program, conversation topics centered on the content of these programs, and people's perceived degree of threat associated with these programs. Our basic thesis was that the more frightening a television program, the more enjoyment and entertainment people expect from it, the more they tend to select it for viewing, and the more they like to talk about it in subsequent conversations.

Correspondence concerning this article should be addressed to Etienne Mullet, 17 bis rue de Quefes, F-31830 Plaisance, France. E-mail: etienne.mullet@wanadoo.fr

\section{Self-awareness and negative self-perception}

Moskalenko and Heine (2003) have argued that people seek dramatic entertainment mainly for its ability to distract their attention from themselves (their internal world) by attracting their attention to the external world. Self-awareness is usually perceived as an unpleasant state of mind because there is always a distance between what we believe we actually are and have achieved, and what we believe we might ideally be and have achieved. In other words, self-awareness tends to be associated with negative self-perception. Dramatic experience presents an opportunity to escape the self by taking the role of observer (being an "I"), rather than being observed (being a "me"): The more dramatic the experience, the more it grips people and the more they forget about their private concerns.

Young (2003) measured the relationship between the strength of the dramatic experience and the strength of the fascination it exerts on viewers. Participants in Young's study were undergraduate students. For four minutes, they were presented with a series of ten news clips, some showing somewhat stressful information (Girl chokes on lunch), and some offering relatively trivial information (Zoo celebration). They were then instructed to rank these clips in order of the importance they personally attributed to the news they 
contained. After this ranking task was completed, they were instructed to evaluate each clip on the basis of a series of dimensions: familiarity with the issue depicted in the clip, importance of this issue for the community, unpleasantness (danger, threat) associated with the issue, level of fear generated by the issue, and so on. Unpleasantness, personal impact, and fear were found to be strongly associated with the rankings in terms of news importance. The mean level of fear associated with the most importantly ranked clip was considerably higher than the mean level of fear associated with the least importantly ranked clip, and the trend was linear. Young concluded that the level of fear engendered by a program has strong implications on the perceived importance of news in television programs. He referred to reversal theory (Apter, 2001) as a possible framework for explaining why fear is an unpleasant emotional experience that people generally try to avoid, although they continue to be attracted by news media that indiscriminately report violence and disasters.

The present study aimed to replicate Young's (2003) findings regarding the emotional reasons behind the choice of television programs and to extend it to the case of subsequent conversions about these programs: Why do people like frightening programs? Why are accidents, catastrophes, troubles, and illnesses so interesting and entertaining when displayed on the television screen? Why are they such frequent topics of conversation during coffee breaks? As suggested by Young, this is the type of question reversal theory is especially able to analyze effectively (Apter, 2001; see also, Kerr, 2004; Rutledge \& Tucker, 2007).

\section{Reversal theory}

Reversal theory (Apter, 2001; 2007) is a general theory of motivation, emotion, personality and stress, based on a phenomenological analysis of everyday experience. The basic tenet is that each of us is a different kind of person at different times, so our personality changes during the course of everyday life. Underlying this dynamic is a structure of four opposing pairs of states, each pair representing opposite ways of experiencing the world in some fundamental respect. The pair of states of particular relevance to this study is composed of the so-called telic and paratelic states. The telic state is one in which the goal is experienced as being of overriding importance, and activities are simply means towards that end. The paratelic state is one in which the ongoing activity is experienced to be of central importance, and goals are there to simply to make the activity more interesting. The opposing values here are achievement (telic) and enjoyment (paratelic). The point of view of the telic state is serious and that of the paratelic state is playful.

One of the key phenomenological characteristics that distinguish the states relates to what is known in reversal theory as a "protective frame" (Apter, 1992). This experiential frame, when present, means that the individual feels cut off from significant consequences. This is one of the aspects of playfulness and activity-orientation and is, therefore, a defining feature of the paratelic state. The goal-oriented telic state, by contrast, lacks this frame and as a result is aware of consequences, including the serious consequences of things going wrong. A further contrasting characteristic of the two states is that in the telic state one finds any kind of arousal to be unpleasant. It can be experienced as, for example, anxiety. In the paratelic state, arousal is pleasant and is experienced instead as a form of pleasurable excitement. In other words, in the playful paratelic state, anything threatening or risky will be experienced as enjoyable, provided a reversal to the telic state does not occur. Thus a reversal represents an abrupt change in the way stimulating or arousing situations are experienced. Emotions that are unpleasant in the telic state, such as anxiety, but that are experienced as pleasant in the paratelic state, are known in the theory, in their pleasant form, as parapathic emotions.

Consequently, from the reversal theory perspective, threatening situations will tend to be experienced as unpleasant in the telic state and as pleasant in the paratelic state, because of the protective frame. The stronger the protective frame, the more the individual will be able to face up to threats and, seemingly paradoxically, convert the resulting arousal into pleasure. A protective frame may be an entirely personal way of viewing things at a particular moment, but more often there are features of the situation that help to establish such a frame. One of these (Apter, 1992) is the frame in which one sees oneself to be a mere observer (a "me" in Moskalenko and Heine's terminology) of the threatening situation and not directly involved (an "I" in this terminology) (see also Sparks, Spirek \& Hodgson, 1993). This is used by spectators of dangerous sports, audiences of thriller movies, and so on, and will be the kind of protective frame to be investigated in the present experiment. In terms of television, reversal theory suggests that the distance created by the medium usually allows us to enjoy arousing material within a protective frame, even if the material is about unpleasant events (see also Hill, 2000).

It is also possible to add protective frames to each other in order to make the overall protective frame increasingly robust. For example, people discussing something dangerous that is now in the past will be experiencing the danger through a protective frame. This means that people who are discussing something dangerous or unpleasant that was merely observed in the past will be experiencing the danger through two protective frames and will be particularly likely to find the conversation pleasant and resist a reversal into the telic state. In this study we will also include the use of multiple protective frames. 


\section{Hypotheses}

As in Young's (2003) study, we make use of a series of questionnaires assessing the same more or less threatening situations from different points of view. The first point of view is that of actuality; that is, the one in which what happens is something that actually happens to the person in the real world, and the possible negative consequences of what happens are actually suffered by that person (corresponding to the perceived unpleasantness condition in Young). From this no-protective-frame viewpoint, participants were instructed to consider a series of items representing various levels of more or less painful or catastrophic situations and assess the degree of threat they currently associate with these situations. We expected these assessments to be strongly correlated to independent assessments made later using classical risk perception scales (Chauvin, Hermand, \& Mullet, 2007).

The second point of view is that of the visual depiction of reality; here, what happens does not happen to the observers but is merely observed by them and, as a result, the consequences of what happens are not actually suffered directly. From this one-protective-frame viewpoint, participants were instructed to consider a series of more or less interesting and entertaining television programs that completely paralleled the series of actual painful or catastrophic situations and to assess the degree of interest and entertainment they associate with these programs (corresponding to the personal importance condition in Young's study). This allowed a direct comparison between threat assessments from the first point of view and interest and entertainment assessments from the second point of view.

Our first hypothesis (H1), directly borrowed from Young's (2003) results, was that the overall mean score of the threat attributed to the actual situations would be positively correlated with the overall mean score of the interesting and entertaining character attributed to the corresponding television programs. An auxiliary hypothesis (H1a) was that both scores would also be correlated with participants' selfreported television habits; that is, participants would tend to report having more frequently watched frightening television programs (the ones also adjudged to be more entertaining) than television programs corresponding to non-threatening situations.

A second hypothesis ( $\mathrm{H} 2)$, borrowed from reversal theory, was that among a minority of participants, the individual scores of the threatening character attributed to the actual situations should be negatively correlated with the individual scores of the interesting and entertaining character attributed to the corresponding television programs. We expected the playful paratelic state to correspond with television viewing in general, where anything threatening or risky will be experienced as enjoyable. However, for a minority of the participants, we expected the perceived threat from the television programs to be so strong that a reversal to the telic state would spontaneously occur. As a result, we expected this minority of participants to inversely score the threatening situations and the corresponding television programs, while the majority of the participants would score the threating situations and their corresponding television programs similarly.

The third point of view is that of the verbal evocation of the reality: a two- protective-frame condition. This condition was obtained by instructing the participants to imagine that they are in a train compartment with someone with whom they could converse about a recent television program. They were to assess different possible conversation topics depending on their willingness to take part in the conversation. In fact, the series of conversation topics completely paralleled the series of actual threatening situations in such a way that, as in the previous condition, a direct comparison between degree of threat assessment and degree of inclination to take part in the conversation might be compared.

Our third hypothesis (H3) was that the assessments of the threatening situations would be more strongly correlated with the willingness to take part in conversation about such situations than with the assessments of the interesting and entertaining character of the situations when presented on television. An auxiliary hypothesis (H3a) was that conversation topic assessments would be more strongly correlated to participants' risk perception assessments than interest and entertainment programs are. The fourth and last point of view was that of the verbal evocation of past reality: the familiarity condition in Young's study. This was obtained by instructing the participants to report on the different occurrences in their lives that may have corresponded to one or more of the situations presented in the previous reality condition. This viewpoint was used as a control condition. Our fourth hypothesis (H4), based on Young's findings, was that the correlation should be lower than +.10 ; that is, close to zero or negative.

\section{Method}

\section{Participants}

The participants were 153 students (124 females and 29 males) from Barcelona, recruited on a voluntary basis. They were aged 19 to $27(M=21.27, S D=3.44)$. Participants were contacted through psychology courses. The acceptance rate was high: $82 \%$ of the people contacted agreed to participate in the study.

\section{Material}

Six questionnaires were used:

1. The No Protective Frame questionnaire. This was composed of a list of 15 more or less painful situations. These situations ranged from cycling to being caught in an earthquake. They are described in Table 1.

2. The One Protective Frame questionnaire. This was composed of a list of 15 more or less interesting television 
Table 1

The 15 Situations

\begin{tabular}{|c|c|c|}
\hline & Real Life Condition & TV Program Condition \\
\hline Elevator & $\begin{array}{l}\text { During your holidays in a foreign country there is an } \\
\text { earthquake while you are inside an elevator. The eleva- } \\
\text { tor is blocked and you can't get out. }\end{array}$ & $\begin{array}{l}\text { You watch, in a live broadcast, a report about the } \\
\text { catastrophe of a serious earthquake. This report in- } \\
\text { cludes many sequences about people trapped in eleva- } \\
\text { tors, which have been recorded by security cameras. }\end{array}$ \\
\hline Train & $\begin{array}{l}\text { You are a passenger on a derailed train which is on the } \\
\text { point of falling. }\end{array}$ & You watch, in a live broadcast, a derailed train. \\
\hline San Fermin & $\begin{array}{l}\text { You are participating in the running of the bulls } \\
\text { ("encierro") in Pamplona's San Fermin festival. You } \\
\text { are running behind two bulls and one of them suddenly } \\
\text { turns towards you. }\end{array}$ & $\begin{array}{l}\text { You watch a report about the running of the bulls } \\
\text { ("encierro") in Pamplona's San Fermin festival. You } \\
\text { can see a person running behind two bulls and one of } \\
\text { them suddenly turns towards him. }\end{array}$ \\
\hline Quarrel & $\begin{array}{l}\text { You are in demonstration and suddenly, close to you, } \\
\text { a very violent quarrel breaks out between one young } \\
\text { demonstrator group and an opposing group. }\end{array}$ & $\begin{array}{l}\text { You watch a report on violence at demonstrations. This } \\
\text { report includes many violent sequences which have } \\
\text { been recorded in the foreground. }\end{array}$ \\
\hline Stitch & You watch while a deep cut in your forearm is stitched. & $\begin{array}{l}\text { You watch a report on emergency surgery which in- } \\
\text { cludes many sequences showing deep cuts on limbs be- } \\
\text { ing stitched. }\end{array}$ \\
\hline Wrestling & You take part in an unprofessional wrestling bout. & You are present at an unprofessional wrestling bout. \\
\hline Drug & You are totally drugged (with substances like ecstasy). & $\begin{array}{l}\text { You watch a report on the effects of "designer" drugs } \\
\text { on behavior. This report includes many sequences } \\
\text { about the common behavior of people who are totally } \\
\text { drugged. }\end{array}$ \\
\hline Immersion & You dive very deep in a nuclear submarine. & $\begin{array}{l}\text { You watch a report on a nuclear submarine immersion. } \\
\text { This report includes many sequences, recorded inside } \\
\text { the submarine, showing the effects of deep immersion } \\
\text { on the passengers. }\end{array}$ \\
\hline Dentist & You have your wisdom tooth pulled out. & $\begin{array}{l}\text { You watch a report on dentistry. This report includes } \\
\text { many sequences about wisdom teeth being extracted. }\end{array}$ \\
\hline Blood Sample & Your blood is being extracted for testing. & $\begin{array}{l}\text { You watch a report on blood testing. This report in- } \\
\text { cludes many sequences showing people's blood being } \\
\text { extracted. }\end{array}$ \\
\hline Cooking & You are cooking and you are spattered with boiling oil. & $\begin{array}{l}\text { You watch a cooking program on how to decrease the } \\
\text { risk of burns. This report includes many sequences } \\
\text { showing second degree burns. }\end{array}$ \\
\hline Skating & In a skating rink you crash with another skater. & $\begin{array}{l}\text { You watch a report on skating accidents. This report } \\
\text { includes many sequences showing collisions in small } \\
\text { ice rinks in which many people are skating at the same } \\
\text { time. }\end{array}$ \\
\hline Tattooing & You are getting a tattoo done (back, arms, legs...). & $\begin{array}{l}\text { You watch a report on tattooing (back, arms, legs...). } \\
\text { This report includes many sequences showing live } \\
\text { broadcasts of tattooing. }\end{array}$ \\
\hline Skiing & You are skiing. & $\begin{array}{l}\text { You watch a report on skiing. This report includes many } \\
\text { sequences showing amateur skiers. }\end{array}$ \\
\hline Biking & $\begin{array}{l}\text { You ride on bike through a residential area with almost } \\
\text { no traffic. }\end{array}$ & $\begin{array}{l}\text { You watch a scene in which a person is riding a bike } \\
\text { through a residential area with almost no traffic. }\end{array}$ \\
\hline
\end{tabular}


Table 2

Means and Standard Deviations Observed for the 15 Situations for the Six Viewpoints

\begin{tabular}{|c|c|c|c|c|c|c|c|c|c|}
\hline \multirow[b]{5}{*}{ Item } & \multirow{4}{*}{\multicolumn{2}{|c|}{$\begin{array}{l}\text { Threat } \\
\text { Q \#1 } \\
0 \text { PF }\end{array}$}} & \multicolumn{4}{|c|}{ Interest and Entertainment } & Personal & \multirow{5}{*}{$\begin{array}{c}\text { Habits } \\
\mathrm{Q} \# 5 \\
M\end{array}$} & \multirow{5}{*}{$\begin{array}{c}\text { Perceived } \\
\text { Risk } \\
\text { Q \#6 } \\
\\
M\end{array}$} \\
\hline & & & \multirow{3}{*}{\multicolumn{2}{|c|}{$\begin{array}{c}\text { Watch TV } \\
\text { Q \#2 } \\
1 \text { PF }\end{array}$}} & \multirow{3}{*}{\multicolumn{2}{|c|}{$\begin{array}{c}\text { Talk about TV } \\
\text { Q \#3 } \\
2 \text { PFs }\end{array}$}} & \multirow{4}{*}{$\begin{array}{c}\text { Experience } \\
\text { Q \#4 } \\
M\end{array}$} & & \\
\hline & & & & & & & & & \\
\hline & & & & & & & & & \\
\hline & $M$ & $S D$ & $M$ & $S D$ & $M$ & $S D$ & & & \\
\hline Elevator & 2.02 & 1.60 & 6.67 & 4.35 & 3.38 & 2.41 & 1.48 & 4.99 & 7.91 \\
\hline Train & 2.07 & 1.78 & 7.11 & 4.15 & 4.27 & 2.63 & 8.35 & 4.68 & 7.13 \\
\hline San Fermin & 4.32 & 2.18 & 7.91 & 3.36 & 7.98 & 3.55 & 1.27 & 3.94 & 6.63 \\
\hline Quarrel & 5.76 & 2.40 & 5.15 & 2.89 & 5.07 & 2.73 & 3.50 & 6.13 & 5.75 \\
\hline Stitch & 6.07 & 2.81 & 7.92 & 4.33 & 6.85 & 3.78 & 2.42 & 3.19 & 4.46 \\
\hline Wrestling & 7.01 & 2.74 & 11.28 & 3.47 & 10.88 & 3.40 & 1.13 & 2.34 & 5.89 \\
\hline Drug & 7.26 & 3.05 & 2.57 & 2.00 & 3.01 & 2.32 & 1.78 & 6.92 & 7.97 \\
\hline Immersion & 7.30 & 2.94 & 6.61 & 3.45 & 7.48 & 3.44 & 1.47 & 1.97 & 4.99 \\
\hline Dentist & 8.77 & 2.86 & 10.62 & 3.20 & 10.93 & 2.94 & 3.93 & 1.44 & 3.12 \\
\hline Blood Sample & 10.35 & 3.11 & 9.77 & 3.42 & 9.72 & 3.42 & 5.24 & 2.37 & 2.32 \\
\hline Cooking & 10.55 & 2.90 & 9.41 & 3.24 & 9.56 & 3.15 & 4.03 & 2.16 & 4.85 \\
\hline Skating & 10.77 & 2.55 & 9.12 & 2.92 & 10.57 & 2.39 & 3.72 & 1.92 & 4.04 \\
\hline Tattooing & 10.81 & 2.53 & 5.63 & 3.57 & 6.31 & 3.30 & 1.54 & 3.41 & 3.89 \\
\hline Skiing & 12.13 & 2.24 & 7.76 & 4.45 & 10.59 & 3.65 & 4.26 & 4.63 & 4.55 \\
\hline Biking & 14.62 & 1.42 & 12.32 & 3.85 & 13.17 & 2.92 & 6.21 & 2.33 & 3.84 \\
\hline
\end{tabular}

$\mathrm{Q} \#=$ Question number, $\mathrm{PF}=$ Protective Frame

programs. These programs were completely parallel to the painful situations invoked in the first questionnaire. They ranged from a program showing people cycling to a program bluntly reporting on an earthquake. They are described in Table 1.

3. The Two Protective Frames questionnaire. This was composed of a list of 15 more or less interesting conversations about television programs. These programs were the same as the ones evoked in the second questionnaire.

4. The Personal Experience questionnaire. This was composed of the same list of 15 more or less painful situations used in the first questionnaire, plus 6 additional situations, used as distracters. Next to each situation there was an 11point response scale labeled from Never been in this kind of situation to Often been in this kind of situation.

5. The Television Habits questionnaire. This was composed of the same list of 21 situations used in the fourth questionnaire. By each situation, there was an 11-point response scale labeled from I have never watched a program about this kind of situation to I have frequently watched programs about this kind of situation.

6 . The Risk Perception questionnaire. This was composed of the same list of 21 situations used in the fourth and fifth questionnaires. By each situation, there was an 11-point response scale labeled from No risk to Extremely risky.

\section{Procedure}

The administration of the questionnaires was partly counterbalanced. Participants were divided into three groups. As in Young (2003), the procedure used for the first three questionnaires was a ranking procedure. The first group of participants $(N=51)$ was first presented with the No Protective Frame questionnaire. They were invited to consider all 15 situations and select the one that if experienced in daily life would appear to be the most threatening. Once selected, this situation was assigned a rank of 1 , and deleted. Participants were then invited to consider all 14 remaining situations and select, again, the one that appeared to be the most threatening. Once selected, this situation was assigned a rank of 2 , and deleted, and so on until there was only one situation remaining that was ranked 15 .

Next we presented this group of participants the One Protective Frame questionnaire. Participants were invited to consider all 15 television programs (which corresponded to the 15 previously considered situations) and rank them in terms of interest and entertainment using the same procedure.

Next these participants were presented with the Two Protective Frames questionnaire. Participants were invited to imagine they were traveling by train and that a conversation about a recent television program ensued between two people in the same compartment. They were presented with a set of 15 possible conversation topics paralleling the 15 television programs shown in the previous list. They were instructed to rank them in terms of willingness to participate using the same procedure. In this way, each participant produced a personal ranking of items in each of the first three questionnaires. 
Table 3

The 15 Situations Ordered by the Mean of the Participants' Responses for the Six Viewpoints

\begin{tabular}{lcccccc}
\hline & & \multicolumn{2}{c}{ Interest and Entertainment } & Personal & TV & Perceived \\
& Threat & Watch TV & Talk about TV & Experience & Habits & Risk \\
& Q \#1 & Q \#2 & Q \#3 & Q \#4 & Q \#5 & Q \#6 \\
& 0 PF & 1 PF & 2 PFs & & & \\
\hline 1 & Elevator & Drug & Drug & Wrestling & Dentist & Blood Sample \\
2 & Train & Quarrel & Elevator & San Fermin & Skating & Dentist \\
3 & San Fermin & Tattooing & Train & Immersion & Immersion & Biking \\
4 & Quarrel & Immersion & Quarrel & Elevator & Cooking & Tattooing \\
5 & Stitch & Elevator & Tattooing & Tattooing & Biking & Skating \\
6 & Wrestling & Train & Stitch & Drug & Wrestling & Stitch \\
7 & Drug & Skiing & Immersion & Stitch & Blood Sample & Skiing \\
8 & Immersion & San Fermin & San Fermin & Quarrel & Stitch & Cooking \\
9 & Dentist & Stitch & Cooking & Skating & Tattooing & Immersion \\
10 & Blood Sample & Skating & Blood Sample & Dentist & San Fermin & Quarrel \\
11 & Cooking & Cooking & Skating & Cooking & Skiing & Wrestling \\
12 & Skating & Blood Sample & Skiing & Skiing & Train & San Fermin \\
13 & Tattooing & Dentist & Wrestling & Blood Sample & Elevator & Train \\
14 & Skiing & Wrestling & Dentist & Biking & Quarrel & Elevator \\
15 & Biking & Biking & Biking & Train & Drug & Drug \\
\hline
\end{tabular}

$\mathrm{Q} \#=$ Question number, $\mathrm{PF}=$ Protective Frame

Next we presented these participants with the Personal Experience questionnaire and asked them to indicate the extent to which they had previously actually been exposed to each of the $21(15+6)$ situations, using the response scales. Then the participants were presented with the Television Habits questionnaire and asked to indicate the extent to which they had previously watched these types of programs over the previous 24 months, using the response scales. Finally, participants were presented with the Risk Perception questionnaire and asked to indicate the degree of risk they associate to each situation, using the response scales.

For the second group of participants $(N=51)$, we presented the instruments in the following order: One Protective Frame, Two Protective Frames, No Protective Frame, Television Habits, Risk Perception, and Personal Experience. The third group of participants $(N=51)$ received the instruments in this order: Two Protective Frames, No Protective Frame, One Protective Frame, Risk Perception, Personal Experience, and Television Habits. As a result, the No Protective Frame questionnaire, the One Protective Frame questionnaire, and the Two Protective Frames questionnaire were presented in first position to one-third of participants, in second position to another third of participants, and in third position to the remaining third of participants.

\section{Results}

Results from the three groups of participants were pooled together after group differences regarding means were found to be non-significant. The means and standard deviations observed overall for each item are shown in Table 2. For threatening situations, the lowest mean ranked items (the most threatening) were being caught in an elevator during an earthquake, being on a derailed train, and participating in the San Fermin running of the bulls in Pamplona. By contrast, the highest mean ranked items (the least threatening) were skiing and biking. Standard deviations ranged from 1.42 to 3.11 , with a median at 2.55 . There was a reasonable betweensubjects agreement about what constitutes a threatening situation.

For the interesting and entertaining character of the television programs (representing a single protective frame), the lowest mean ranked items (the most interesting) were the program on drugs, the program on quarrels, and the program on immersion. The highest mean ranked items (the least interesting) were the program on wrestling and the program on biking. Standard deviations ranged from 2.00 to 4.45 , with a median at 3.45. There was more between-subject disagreement about what constitutes an entertaining program than about what constitutes a threatening situation.

For the interesting character of conversation topics, the lowest mean ranked items (the most interesting) were the program on drugs, the program on earthquake (elevator), and the program on train accidents. The highest mean ranked items (the least interesting) were the conversation about dentistry and the conversation about biking. Standard deviations ranged from 2.41 to 3.78 , with a median at 3.15 . There was slightly less between-subject disagreement about what constitutes an inviting conversation topic than about what constitutes an entertaining television program. 
Table 4

Correlations between the Assessments Performed under the Six Viewpoints

\begin{tabular}{lcccccc}
\hline & \multicolumn{2}{c}{ Interest and Entertainment } & Personal & \multicolumn{2}{c}{ TV } & Perceived \\
& Threat & Watch TV & Talk about TV & Experience & Habits & Risk \\
& Q \#1 & Q \#2 & Q \#3 & Q \#4 & Q \#5 & Q \#6 \\
& 0 PF & 1 PF & 2 PFs & & & \\
\hline Threat & 1.00 & .43 & .74 & -.19 & .46 & .73 \\
Watch TV & .43 & 1.00 & .87 & -.32 & .79 & .57 \\
Talk about TV & .74 & .87 & 1.00 & -.22 & .77 & .72 \\
Personal Experience & -.19 & -.32 & -.22 & 1.00 & -.08 & -.25 \\
TV Habits & .46 & .79 & .77 & .08 & 1.00 & .72 \\
Perceived Risk & .73 & .57 & .72 & -.25 & .72 & 1.00 \\
\hline
\end{tabular}

$\mathrm{Q} \#=$ Question number, $\mathrm{PF}=$ Protective Frame

An ANOVA was conducted on the three series of SD values with Condition (Threatening, One Protective Frame, Two Protective Frames) as the independent factor. It showed that the differences between conditions were significant, $F(2,28)=13.07, p<.001$. Post-hoc analyses using Tukey's HSD test showed the SD values found in the Two Protective frame condition were not significantly different from the ones found in the two other conditions.

For personal experience of each of the 15 situations, the highest mean ratings were for a train accident, blood sample, and cycling. For television habits, the programs most watched were about drugs and crowd demonstrations (quarrel). Finally, for perceived risk, the situations judged most risky were being in an elevator during an earthquake, train accidents, and drugs.

Table 3 shows the 15 situations ordered as a function of the participants' mean responses in each condition. Spearman rank correlation coefficients computed on the group level; that is, between the columns in Table 2, are shown in Table 4. Between mean ranks in the Zero Protective Frame condition and mean ranks in the One Protective Frame condition, the correlation was .43. The more a situation was judged threatening when there was no protection from its actual consequences, the more it tended to be adjudged to be interesting and entertaining when one was only indirectly exposed to it. Between mean ranks in the Zero Protective Frame condition and mean ranks in the Two Protective Frames condition, the correlation was significantly higher: $.74, p<.01$. The more a situation was considered to be threatening when there is no protection, the more it tended to be considered an inviting conversation topic.

Overall, correlations involving personal experience were negative (and generally lower). There was not much relationship between assessed personal experience and the other measurements. Television habits were correlated to mean rankings about the interesting and entertaining character of the programs and the inviting character of corresponding conversation topics. Television habits were also correlated to the means of the perceived risk ratings. The more a situation is considered to be risky, the more people report having watched programs dealing with these situations. Finally, risk perception was correlated to mean ratings for the threatening character of the situations and the mean ratings for the inviting character of conversation topics.

Spearman rank correlation coefficients were computed on the individual level. For the individual correlations between ranks in the Zero Protective Frame condition and ranks in the One Protective Frame condition (see Figure 1), the most interesting finding was in the form of their distribution (skewness $=-.47$, kurtosis $=-.62$ ). The histogram was bimodal, with a majority of participants with positive correlations, peaking at about $.40 / .50$, and a minority of participants with negative correlations, peaking at about $-.40 /-.50$. The effect of gender, assessed trough $t$-test performed on transformed correlations values (into $z$ values), was not significant. For the individual correlations between ranks in the Zero Protective Frame condition and ranks in the Two Protective Frames condition (see Figure 2), the histogram also showed bimodality (skewness $=-.47$, kurtosis $=-.58$ ), with a majority of participants with high positive correlations, peaking at about .50/.60, and a minority of participants with low correlations, peaking at about $.00 / .10$. Between these two distribution means, the difference was statistically significant, $t(152)=-7.56, p<.001$. The effect of gender was not significant. The correlation between the two series of values was also significant: $.42, p<.001$.

\section{Discussion}

This study examined the psychological links that may exist between people's choices of television programs, conversation topics centered on the content of these programs, and people's perceived degree of threat associated with these programs. It was conducted within the framework of reversal theory (Apter, 2001).

Our first hypothesis (H1) was that the threatening character of real life situations would be positively associated with 


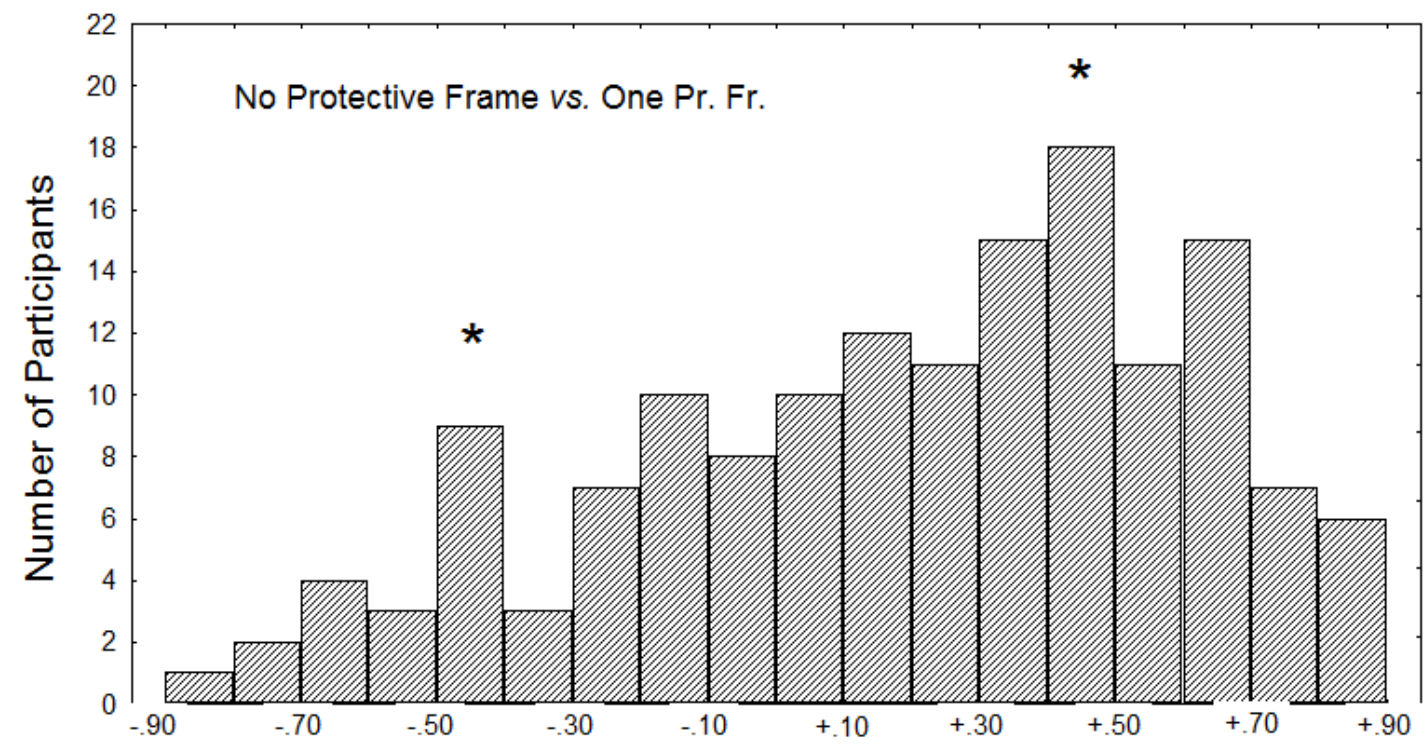

Figure 1. Distribution of the Spearman rank correlation coefficients computed on an individual basis between the zero-frame condition and the one-frame condition. The stars show the modes of the distributions.

the interesting and entertaining character that these same situations would have when reported on television (i.e. with a single protective frame). This is what we found. Although the correlation was not very high, it did point in the expected direction. This result was consistent with Young's (2003) findings showing a positive association between degree of fear associated with a program and level of interest manifested for this program. It was consistent with Zillman, Knobloch and Yu's (2001) findings showing that participants preferentially chose to read and dedicated more time to reading articles accompanied by photographs depicting violent situations than texts accompanied by innocuous photographs or no photograph at all. It was consistent with Cho et al.'s (2003) suggestion that "television news leads people to become emotionally aroused, with these activated emotional responses concurrently driving future television news use" (p. 324). It was also consistent with the overall conclusion of Hoffner and Levine's (2005) review of the determinants of media enjoyment: Considering how viewers interpret or appraise their reactions to fright and violence was deemed as essential if one wants to understand entertainment.

More generally, these results were consistent with transportation theory (Green, Brock \& Kaufman, 2004), which suggests that enjoyment can be derived from the experience of being immersed in a narrative, unreal world, as well as from the consequences of the immersion, and with the Goldenberg, Pyszczynski, Johnson, Greeberg, and Solomon (1999) proposal that vicarious experience of tragedy, through film and literature, provides a safe, and as a result, enjoyable way of coping with the fear associated with the idea of one's inescapable death.
Our auxiliary hypothesis (H1a) was that threat and entertainment scores would be positively correlated to participants' self-reported television habits. This is what we observed. In particular, participants reported having more frequently watched television programs corresponding to highly threatening situations than television programs corresponding to non-threatening situations.

The second hypothesis (H2), borrowed from reversal theory, was that, among a minority of participants, the relationship between the threatening character attributed to the actual situations and the interesting and entertaining character attributed to the corresponding television program should be negative. This is what we found. For a majority of individuals, the more a situation was judged to be threatening when there was no protection from its actual consequences, the more it tended to be considered interesting and entertaining when one was only indirectly, visually, exposed to it. But, for a minority of individuals, the more a situation was judged to be threatening when there was no protection, the less it tended to be considered interesting and entertaining even when one was only visually exposed to it. In other words, the protective frame used was not effective for all the participants. Watching accidents and catastrophes on television remains truly displeasing to a minority of people, due to the psychological (non-physical) consequences associated with merely seeing them. This result was consistent with Hoffner and Levine's (2005) review showing that individuals with greater empathy and those who are less sensationseeking and aggressive reported less enjoyment of horror and violence in television programs. 
The third hypothesis (H3) was that the threatening character of real life situations should be more strongly associated with the inviting character of conversation topics centered on television programs than with the interesting and entertaining character of these same television programs. This is what was observed. The correlation observed may be considered high. Individual analyses, however, showed that, as in the case of television programs, this was only true for one part of the sample (about two-thirds). For a minority of participants, the association was notably lower. This, again, is highly instructive. The two protective frames used together were effective for all the participants, but not to the same extent. In addition, the participants for whom the first protective frame was ineffective tended to be the ones for whom the second protective frame, although influential, was not effective enough to completely reverse high threat to high interest and entertainment. Among these people, conversing about accidents and catastrophes may still be a somewhat painful activity.

An auxiliary hypothesis ( $\mathrm{H} 3 \mathrm{a})$ was that conversation topic assessments should be more strongly correlated to participants' risk perception assessments than interest and entertainment programs are. This is what we observed. Interesting conversation topics possibly tend to include more risky issues than interesting television programs, other things being equal.

The fourth hypothesis (H4) was that the association between personal experience of accidents, catastrophes and other risks should be low. This is what we observed and this finding was consistent with Young's (2003) findings. As a result, it can be stated that the associations found between the five other variables introduced in the study were not contaminated by possible, uncontrolled, individual differences between participants with respect to the threatening situations in which they may have found themselves in the past.

\section{Limitations}

The main limitation of the study resides in the way the sample was constituted. Participants were volunteers, and the sample was composed mainly of female students. As females have a tendency to have and display more anxiety than males, this may have affected the results. As a result, the value of the present study is not in precisely estimating the size of the correlation between the different factors considered in the study but in adding evidence on the way perceived threat and anticipated enjoyment, or perceived threat and risk perception are related the one with the other. Future studies using more representative samples, and bearing on different types of violent situations (e.g., violence in sport) are needed.

A second limitation resides in that the order in which the conditions were presented was not completely randomized. Future studies, using larger samples, should more systematically examine if the responses observed under one condition (e.g., presence of one protective frame) differ whether this condition was the first in which the participants were placed or whether participants were initially placed in another condition such as presence of two protective frames or threat assessment. Interesting hypotheses could be tested. For instance: To what extent is the report of television programs immediately before assessing threat sufficient to establish at least a limited protective frame?

A third limitation resides in that each participants' level of telic-paratelic dominance has not been assessed at some time during data gathering. It would have been very instructive to relate each participant's dominance score and his/her position in each of the distributions shown in Figures 1 and 2.

A fourth limitation resides in the level of measurement. Future studies should replicate the present one using interval level data, rather than ranked data. In addition, using rating scales would allow for multivariate analyses (e.g., regression) that could test the contribution of one vs. two protective frames on interest or enjoyment, as well as including prior actual history with each event as a covariate. Gender might also be included as a factor in a regression, with sufficient sample.

\section{Implications}

The first overall conclusions were that (a) most people like to watch television programs showing very risky and threatening situations probably because these situations are the most entertaining ones once their negative consequences have been removed, and (b) most people like to choose conversation topics centered on threatening and risky situations probably for the same reason. The implications are straightforward: television companies are probably right to so heavily broadcast such programs because they are the ones that most people really tend to enjoy the most, and as a result, tend to watch the most, and that most people tend to recommend to their friends and relatives. As most broadcasters financially depend on advertising, they are bound to behave in a way that maximizes their audience ratings (Tai, 2000). Efforts by television stations to offer family sensitive newscasts that eliminate unnecessarily violent images will possibly only result in decreased audiences even if the majority of audience members indicated their dissatisfaction with the high level of violence shown in newscasts (Lafayette, 1995).

The second overall conclusions were that (c) some people dislike watching television programs that show very risky situations because these situations, although not real for them, are still very stressful, and possibly psychologically harmful, and (d) some people do not preferentially choose conversation topics centered on risks and risky situations for the same basic reason. Because of this, the owners of television channels, who, for financial reasons, are strongly inclined to avoid losing even a small share of their potential audience, are also 


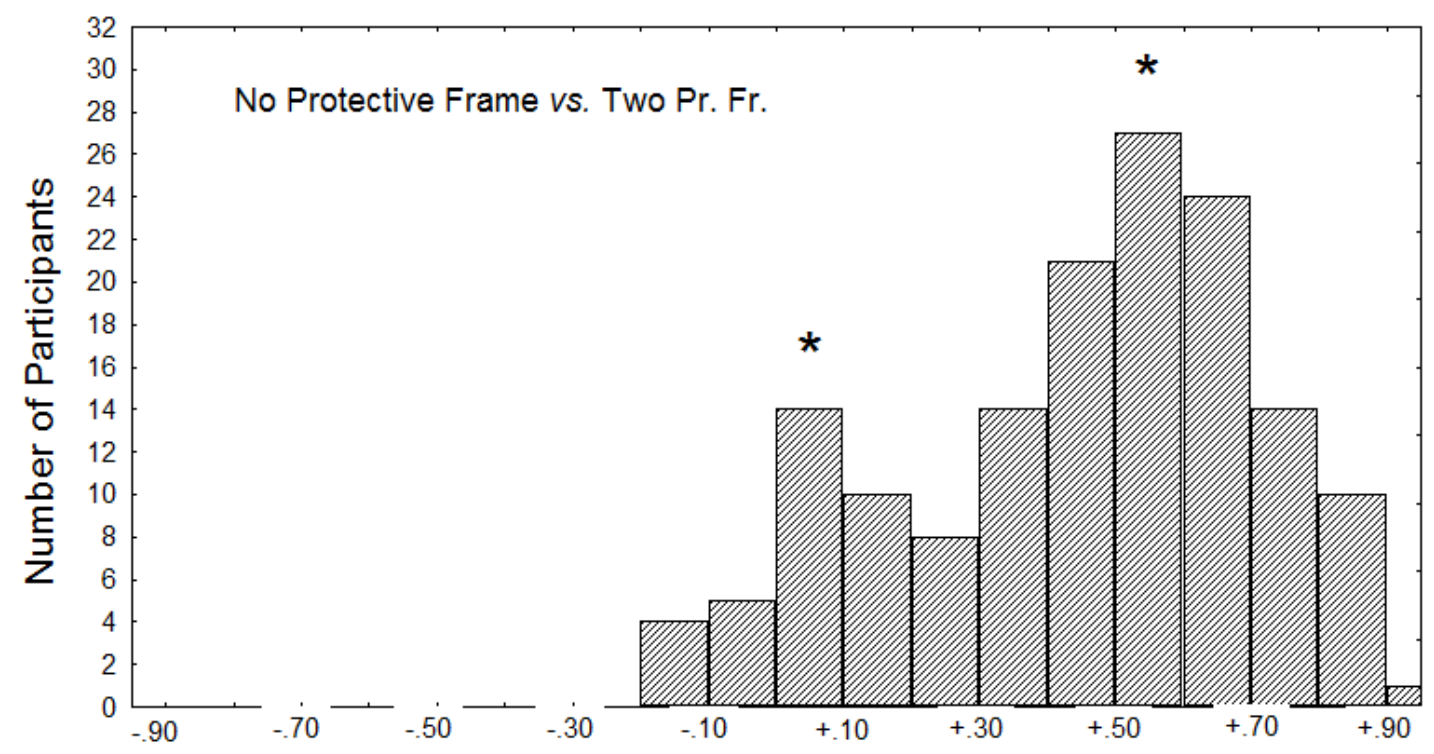

Figure 2. Distribution of the Spearman rank correlation coefficients computed on an individual basis between the zero-frame condition and the two-frame condition. The stars show the modes of the distributions.

probably right to include in their programming some purely innocuous programs (e.g. soap operas), programs in which nothing seems to happen in the view of other, less sensitive people. Broadcasters are also probably right to warn viewers about potentially stressful program content.

As regards risk perception and specifically crime perception in the environment, one possible, direct consequence of these preferences for frightening programs is that people tend to have a partly misshapen view of reality. As a result, people's perspective on societal risks (for example their magnitude, their order of priority, and the amount of money to be spent on protection from them) may be substantially biased (see Kpanake, Chauvin, \& Mullet, 2008). As shown by Diefenbach and West (2001), there is a positive relationship between television exposure and beliefs about crime rates in the community (see also Goidel, Freeman \& Procopio, 2006).

Finally, the suggestion that people tend to select frightening programs on television because they tend to enjoy them is not contrary to Shoemaker's (1996) suggestion that all human beings are, for biological and evolutionary reasons, strongly motivated to monitor the world around them. From an evolutionary perspective, information about potential threats in the environment (e.g., presence of predators), has still more survival value than information about positive aspects of the environment (e.g., presence of food). Our suggestion is that, in addition to the basic, vital need to keep up to date, people also experience a need for enjoyment, and that some form of enjoyment is associated to the viewing of threatening situations once the immediate consequences of these situations are removed. It is in this sense that reality (in fact, "edited" reality) may frequently be declared more compelling than fiction.

\section{Protective frame, risk communication through the media and subsequent risk behavior}

On a more theoretical level, the concept of the protective frame has been shown in this study to be a useful one for understanding apparent contradictions between people's preferences in actual daily life and people's preferences in "reported" daily life. Because of one or more protective frames, threatening situations that are normally experienced as being the most unpleasant in real life may also be the very ones that are most "enjoyed" when reported in the media.

More generally, the protective frame concept is potentially useful in the domain of risk communication, risk perception, and risk behavior (Gerkovich, 2001). It may help to synthesize a host of parallel findings. It may explain, for example, why fearful people perceive themselves to be more at risk than non-fearful people, why angry people perceive themselves to be less at risk than non-angry people (Lerner, Gonzalez, Small \& Fischhoff, 2003), why people tend to prefer risks they believe they can personally control than risks they believe they cannot control (Klein \& Weinstein, 1997), why people try to reduce their perceived similarity to a reputedly risky target (Klein \& Weinstein), why some people engage in more risky sexual behavior with a partner with whom they are in a close relationship than with casual sexual partners (Misovich, Fisher, \& Fisher, 1997), and why intoxicated people usually engage in more risky behaviors than non-intoxicated people (MacDonald, MacDonald, Zanna \& 
Fong, 2000). This is because anger, close intimacy, control, and intoxication are factors that could increase the strength of an existing protective frame or help create a (fictitious) protective frame (which Apter, 1992, has referred to as a 'fallacious frame'). As a result, they tend to contribute to the enjoyment experienced, in these conditions, from the risky situation as well as from the act, even if sometimes the consequences are damaging to the actual individual or others.

By contrast, induced fear, memory of previously experienced traumas, and personal similarity to a target that is said to be at high risk probably decrease the strength of the protective frame or prevent the creation of a protective frame. As a result, they tend to contribute to the distress experienced in these conditions as a result of events that are sometimes completely innocuous. This would be exemplified by people suffering from, among other conditions, chronic anxiety, phobia and post-traumatic stress disorder.

The protective frame concept helps us to understand both why people sometimes enjoy observing and talking about risky or unpleasant situations, and even tend to take unnecessary risks, and why people sometimes avoid thinking or talking about risks even in completely safe circumstances. It has been shown, for example, that during times of societal threat, people tend to chose more meaningful, less frightening television programs (McIntosh, Schwegler \& TerryMurray, 2000).

The concept of protective frame is unique to reversal theory, which makes it the only current theory able to fully explain a host of apparently paradoxical findings, such as human beings' ability to positively experience events (e.g., earthquakes) or objects (e.g., predators) that thousands years of evolution should have led them to experience as unpleasant and threatening (see Marshall Thomas, 2006). More importantly, the concept of protective frame, associated with the concept of reversal, can explain why the objects or events that are usually experienced as the most threatening under some circumstances, such as a lion at the door, can be experienced as the most entertaining and enjoyable under other circumstances, such as a lion in a safari park.

\section{References}

Apter, M. J. (1992). The dangerous edge. New York: Free Press.

Apter, M. J. (Ed.) (2001) Motivational styles in everyday life: A guide to reversal theory. Washington, D.C. : American Psychological Association.

Apter, M. J. (2007). Danger: Our quest for excitement. Oxford: Oneworld Publications.

Chauvin, B., Hermand, D., \& Mullet, E. (2007). Risk perception and personality facets. Risk Analysis, 27, 171-185.

Cho, J., Boyle, M. P., Keum, H., Shevy, M. D., McLeod, D. M., Shah, D. V., \& Pan, Z. (2003). Media, terrorism, and emotionality: Emotional differences in media content and public reactions to the September 11th terrorist attacks. Journal of Broadcasting and Electronic Media, 47, 309327.

Davie, W. R. (2001). Crime and passion: Journalism for the masses? Journal of Broadcasting and Electronic Media, 45, 355-364.

Diefenbach, D. L., \& West, M. D. (2001). Violent crime and Poisson regression: A measure and a method for cultivation analysis. Journal of Broadcasting and Electronic Media, 45, 432-445.

Gerkovich, M.M. (2001). Risk-taking. In, Apter, M. J. (Ed.) Motivational styles in everyday life: A guide to reversal theory. (pp.215-228) Washington, D.C.: American Psychological Association.

Goidel, R. K., Freeman, C. M., \& Procopio, S. T. (2006). The impact of television viewing on perception of juvenile crime. Journal of Broadcasting and Electronic Media, 50, 119-139.

Goldenberg, J. L., Pyszczynski, T., Johnson, K., Greenberg, J., \& Solomon, S. (1999). The appeal of tragedy: A terror management perspective. Media Psychology, 1, 313-329. Green, M. C., Brock, T. C., \& Kaufman, G. F. (2004). Understanding media enjoyment: The role of transportation into narrative worlds. Communication Theory, 14, 311327.

Hill, A. (2000). Fearful and safe: Audience response to British reality programming. Television $\mathcal{G}$ New Media, 1, 193-213.

Hoffner, C., \& Levine, K. J. (2005). Enjoyment of mediated fright and violence: A meta-analysis. Media Psychology, 7, 207-237.

Kerr, J. H. (2004). Rethinking aggression and violence in sport. London: Routledge.

Klein, W. M., \& Weinstein, N. D. (1997). Social comparison and unrealistic optimism about personal risk. In B. P. Buunk and F. X. Gibbons (Eds.), Health, coping, and well-being: Perspectives from social comparison theory (pp. 25-61). Hillsdale, NJ: Lawrence Erlbaum.

Kpanake, L., Chauvin, B, \& Mullet, E. (2008). Risk perception among Togolese villagers without access to the media. Risk Analysis, 28, 193-202.

Lafayette, J. (1995, February 13). Family-sensitive news dips in rating. Electronic Media, pp. 1, 18.

Lerner, J. S., Gonzalez, R., Small, D. A., \& Fischhoff, B. (2003). Effects of fear and anger on perceived risks of terrorism: A national field experiment. Psychological Science, 14, 144-151.

MacDonald, T. K., MacDonald, G., Zanna, M. P., \& Fong, G. T. (2000). Alcohol, sexual arousal, and intentions to use condoms in young men: Applying alcohol myopia theory to risky sexual behavior. Health Psychology, 19, 290-298.

Marshall Thomas, E. (2006). The old way: A story of the first people. New York: Picador. 
McIntosh, W. D., Schwegler, A. F., \& Terry-Murray, R. M. (2000). Threat and media viewing in the United States. Media Psychology, 2, 35-46.

Misovich, Fisher, J. D., \& Fisher, W. A. (1997). Close relationships and elevated HIV risk behavior: Evidence and possible underlying psychological processes. Review of General Psychology, 1, 72-107.

Moskalenko, S., \& Heine, S. J. (2003). Watching your troubles away: Television viewing as a stimulus for subjective self-awareness. Personality and Social Psychology Bulletin, 29, 76-85.

Rutledge, H., \& Tucker, J. (2007). Reversing forward: A practical guide to Reversal Theory. Fairfax, VN: OK.

Shoemaker, P. (1996). Hardwired for news: Using biological and cultural evolution to explain the surveillance function. Journal of Communication, 46, 32-47.

Sparks, G. G., Spirek, M. M., \& Hodgson, K. (1993). Individual differences in arousability: Implications for un- derstanding immediate and lingering emotional reactions to frightening mass media. Communication Quarterly, 41, 465-476.

Tai, Z. (2000). Media of the world and world of the media. Gazette, 62, 331-353.

Tamborini, R., Skalski, P., Lachlan, K., Westerman, D., Davis, J., \& Smith, S. L. (2005). The raw nature of televised professional wrestling: Is the violence a cause for concern? Journal of Broadcasting and Electronic Media, 49, 202-220.

Young, J. R. (2003). The role of fear in agenda setting by television news. American Behavioral Scientist, 46, 16731695.

Zillmann, D., Knobloch, S., \& Yu, H.-S. (2001). Effects of photographs on the selective reading of news reports. Media Psychology, 3, 301-324. 